\title{
A EXPERIÊNCIA DO HOMEM, AO TORNAR-SE PAI, NO CONTEXTO GESTACIONAL E NOS PRIMEIROS MESES DE VIDA DO BEBÊ
}

MAN'S EXPERIENCE WHEN BECOMING A FATHER IN THE GESTATIONAL CONTEXT AND ALONG THE BABY'S FIRST MONTHS

LA EXPERIENCIA DEL HOMBRE AL CONVERTIRSE EN PADRE EN EL CONTEXTO GESTACIONAL Y EN LOS PRIMEROS MESES DE VIDA DEL BEBÉ

\author{
Melissa Plautz Bencke* \\ Cristina Saling Kruel*
}

\begin{abstract}
RESUMO
Este estudo teve como objetivo analisar a experiência do homem, ao tornarse pai, no período gestacional e nos primeiros meses de vida do bebê, com enfoque no vínculo inicial, transgeracionalidade e sexualidade. Participaram da pesquisa cinco homens cujos filhos estavam sendo gestados ou tinham até 1 ano de idade. Foram realizados três encontros em grupo focal, no qual os pais falaram sobre suas experiências familiares. As falas foram gravadas e transcritas, e a análise de conteúdo mostrou que, durante a gestação, os pais sentem dificuldade em direcionar sentimentos amorosos intensos ao filho, pela impossibilidade de contato físico entre eles. Evidenciou-se o desejo dos pais em superar o distanciamento vivenciado na relação com seus próprios pais, aproximando-se afetivamente de seus bebês; assim como o nascimento do bebê afeta a experiência sexual do homem, na qual o distanciamento sexual da companheira é compreendido nos primeiros dias pós-nascimento do filho.
\end{abstract}

Palavras-chave: Paternidade. Relação pai-bebê. Transgeracionalidade. Sexualidade.

\section{ABSTRACT}

This study aims at analyzing a man's experience when becoming a parent during the gestational period and along the first months of the baby's life, focusing on the initial bond, transgenerationality and sexuality. Five men, whose children were in the gestation period or were up to one year old, were part of this study. There were three focal group meetings in which the fathers talked about their family experiences. The talks were recorded and transcribed, and the content analysis showed that during the gestation,

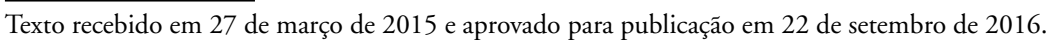

*Psicóloga pelo Centro Universitário Franciscano (Unifra). E-mail: melissabencke@ibest.com.br.

**Doutora, docente na Universidade Franciscana (UFN). E-mail: cristinaskruel@gmail.com. 
fathers find it difficult to direct intense love feelings towards the child due to the impossibility of physical contact between them. The study evidenced fathers' desire to overcome the emotional distance in their relationship with their own parents, by getting affectionately closer to their babies, as well as the way the baby's birth affects a man's sexual experience, in which the distance from the sexual partner is understood in the first days following the child's delivery.

Keywords: Paternity. Father-baby relationship. Transgenerationality. Sexuality.

\section{RESUMEN}

El objetivo de este estudio es analizar la experiencia del hombre al convertirse en padre, en el período gestacional y en los primeros meses de vida del bebé, con enfoque en el vínculo inicial, transgeneracionalidad y sexualidad. Participaron del estudio cinco hombres cuyos niños estaban siendo gestados o tenían hasta un año de edad. Se realizaron tres encuentros en grupo focal, y los padres hablaron sobre sus experiencias familiares. Las conversaciones fueron grabadas y transcritas y el análisis del contenido mostró que durante la gestación, los padres tienen dificultad para dirigir sentimientos de amor intensos hacia el niño por la imposibilidad de contacto físico entre ellos. Se evidenció el deseo de los padres de superar el distanciamiento vivido en la relación con sus propios padres, aproximándose afectivamente de sus bebés; también el nacimiento del bebé afecta a la experiencia sexual del hombre, en la que el distanciamiento sexual de la compañera es comprendido en los primeros días después del nacimiento del hijo.

Palabras clave: Paternidad. Relación padre-bebé. Transgeneracionalidad. Sexualidad.

\section{INTRODUÇÃO}

A paternidade, além de ser uma construção sócio-histórico-cultural (Staudt \& Wagner, 2008), apresenta-se como um processo único, individual, no qual cada homem precisa submergir a sua própria história, suas vivências e experiências pessoais. Com a chegada da paternidade, cabe ao homem uma mudança de papel, em que ele deixa de ser somente filho para se tornar pai (Freitas, Coelho \& Silva, 2007).

Nas últimas décadas, observam-se intensas transformações sociais, culturais e familiares no cenário brasileiro, ocasionadas, em especial, por mudanças legais e econômicas significativas que afetaram as relações familiares. Diante dessas transformações, há a necessidade de serem assumidos papéis diferentes dos desempenhados por geraçôes passadas, tanto no âmbito social quanto no familiar. 
Historicamente, no Brasil, a masculinidade esteve vinculada à virilidade e força, e, atrelada a esse estereótipo, esteve a experiência da paternidade (Freitas et al., 2007; Henningen $\&$ Guareschi, 2002). Atualmente, ao tornarem-se pais, os homens precisam se posicionar diante das exigências de revisão de seus papéis junto aos filhos e à companheira. Espera-se, do homem que é pai, que esteja mais próximo, afetuoso e disponível a seus filhos (Gabriel $\&$ Dias, 2011). Assim, o papel do homem no âmbito familiar encontra-se em processo de redefinição, em consonância com as transformações experienciadas também pelas mulheres e, na experiência paterna, pode coexistir a função tradicional de provedor e de um pai mais presente, envolvido com os cuidados do filho e com maior contato afetivo (Balancho, 2004; Silva, Lamy, Rocha \& Lima 2012; Ferreira et al., 2016).

O tornar-se pai faz parte de uma nova fase de vida do homem, permeada por novas experiências e representaçôes sociais (Freitas et al., 2009). Corroborando tais ideias, Staudt e Wagner (2008) assinalam que as formas de organizar a família e os papéis parentais são influenciadas pelas relações familiares, pela cultura, pela sociedade e pela própria organização psíquica dos sujeitos envolvidos. $\mathrm{O}$ modo de ver e ser no mundo são impulsionados pelos diversos microssistemas que rodeiam os sujeitos, tais como a família, a comunidade nos quais estão inseridos, assim como o grupo de amigos e colegas de trabalho. Então a adaptação do homem à função parental e o tipo de relação que será estabelecida entre pai e filho serão determinados por inúmeros fatores individuais, sociais, culturais e familiares (Krob, Piccinini \& Silva, 2009).

Tendo em vista tais aspectos, este estudo teve como objetivo analisar a experiência do homem ao tornar-se pai no contexto gestacional e nos primeiros meses de vida do bebê, com enfoque no vínculo inicial, aspectos transgeracionais relativos ao cuidado e influência do tornar-se pai na sexualidade desse homem. Este estudo é parte de uma pesquisa maior que objetivou investigar a experiência do homem ao tornar-se pai. A pesquisa que deu origem ao estudo apresentado neste artigo teve como intuito estudar a paternidade em etapa precoce do desenvolvimento do bebê, a fim de se compreenderem aspectos abrangentes dessa experiência que inaugura a paternidade.

\section{MÉTODO}

\subsection{Delineamento e participantes}

Este estudo consiste em uma pesquisa de abordagem qualitativo-descritiva, na qual a pesquisadora se propôs a participar, compreender e interpretar as informações levantadas, buscando descrever a experiência dos participantes (Campos, 2004). Participaram da pesquisa 5 homens, 2 cujos filhos estavam sendo gestados e 3 cujos filhos tinham idade entre 18 dias e 7 meses, sendo que eram gêmeos os que estavam com 7 meses. Quanto aos critérios de inclusão, foram convidados a participar do estudo homens que tivessem filhos sendo 
gestados ou com até 1 ano de idade e que coabitassem com a gestante ou mãe de seu bebê. Os homens poderiam ter outros filhos, e o nível socioeconômico e educacional foi variado.

Os participantes foram selecionados por conveniência (Gil, 2007), pois foram convidados homens que se enquadravam nos critérios de inclusão do estudo e que residiam em um mesmo condomínio residencial. A escolha pelo condomínio se deu por se tratar de um espaço que é habitado por um grande número de moradores onde predominam casais com filhos pequenos. Além disso, os encontros para a coleta de dados foram realizados nas dependências do próprio condomínio, em um espaço de convivência, mas privativo. Isso favoreceu o comparecimento dos homens aos encontros, assim como o clima descontraído e íntimo entre os participantes.

O convite aos participantes foi feito de forma informal, pois os pais foram abordados nas áreas de lazer do condomínio, enquanto brincavam e, ou, passeavam com seus filhos ou com sua esposa gestante. Ao total, 17 pais foram abordados. Destes, 5 pais aceitaram participar e compareceram aos encontros em grupo. Os demais não compareceram ao primeiro encontro e não lhes foi solicitada justificativa quanto à não participação. Nota-se que os 5 participantes do estudo são militares, fato que não foi um critério para a inclusão na amostra, mas uma consequência de o condomínio ter um grande número de moradores dessa categoria profissional.

Para garantir o sigilo de identidade, os pais serão identificados, neste artigo, com a letra $P$, conforme mencionado na tabela a seguir:

Tabela 1. Dados sociodemográficos dos participantes da pesquisa

\begin{tabular}{|c|c|c|c|c|c|}
\hline & P1 & P2 & P3 & $\mathbf{P 4}$ & P5 \\
\hline Idade & 33 & 29 & 36 & 40 & 37 \\
\hline Escolaridade & $\begin{array}{l}\text { Superior } \\
\text { completo }\end{array}$ & $\begin{array}{l}\text { E } \mathrm{n} s \text { i } \mathrm{n} \text { o } \\
\text { médio }\end{array}$ & $\begin{array}{l}\text { S u p e rio r } \\
\text { completo }\end{array}$ & $\begin{array}{l}\text { Superior } \\
\text { completo }\end{array}$ & $\begin{array}{l}\text { Superior } \\
\text { completo }\end{array}$ \\
\hline $\begin{array}{l}\text { Número de } \\
\text { filhos }\end{array}$ & 2 & 1 & 2 & 2 & 2 \\
\hline $\begin{array}{l}\text { Tempo de } \\
\text { gestaçáo ou } \\
\text { idade do bebê } \\
\end{array}$ & 4 meses & $\begin{array}{l}8 \text { meses de } \\
\text { gestação }\end{array}$ & 7 meses & $\begin{array}{l}8 \text { meses de } \\
\text { gestação }\end{array}$ & 18 dias \\
\hline $\begin{array}{l}\text { Idade dos } \\
\text { demais filhos }\end{array}$ & 6 & - & - & 9 & 5 \\
\hline Sexo do bebê & Feminino & Masculino & $\begin{array}{l}\text { Feminino e } \\
\text { masculino }\end{array}$ & Feminino & Feminino \\
\hline
\end{tabular}

Fonte: dados da pesquisa. 


\subsection{Procedimentos de coleta dos dados}

Como instrumento de coleta de dados, foram realizados três encontros em grupo focal, nos quais buscou-se compreender o papel desempenhado pelos homens no período gestacional e nos primeiros meses de vida do bebê, os seus sentimentos em relação às experiências como pais, as facilidades e dificuldades encontradas no processo de tornar-se pai, abrindo-se um espaço de discussão para que os temas emergissem espontaneamente nos relatos das vivências de cada pai participante.

Como disparador do primeiro encontro, a pesquisadora solicitou aos participantes que falassem livremente sobre a experiência com a paternidade atual. Nos encontros seguintes, foram tratados temas de interesse dos participantes, emergidos das discussóes. Cada encontro durou aproximadamente 1 hora e 30 minutos e não havia um roteiro preestabelecido. Os participantes eram convidados a relatar as suas experiências cotidianas com suas famílias, com ênfase na relação com os filhos.

O grupo focal é um grupo de discussão no qual se dialoga sobre um tema em particular (Iervolino \& Pelicioni, 2001). Esse método favorece que trocas, descobertas e participações comprometidas ocorram, proporcionando descontração para que os participantes falem questôes em grupo e não individualmente (Minayo, 2007).

Os encontros foram realizados no salão de festas do condomínio no qual os homens participantes residiam. A coleta foi proposta nesse contexto, por se acreditar que a proximidade do domicílio facilitaria a adesão dos participantes à pesquisa. Durante a coleta, o local esteve privativo, silencioso, sem interferência e interrupçóes de outras pessoas.

No primeiro encontro, os participantes foram informados a respeito dos objetivos do estudo, do método, e todas as suas dúvidas foram esclarecidas. Após as devidas explicações, os participantes assinaram o termo de consentimento livre e esclarecido. Todos os encontros foram gravados e, posteriormente, transcritos. O projeto de pesquisa foi submetido ao Comitê de Ética do Centro Universitário Franciscano, aprovado conforme protocolo número 468.865.

\subsection{Procedimentos de análise dos dados}

Os resultados deste estudo foram tradados por meio da análise de conteúdo (Bardin, 2004). Pela análise das similaridades e particularidades observadas nos discursos dos pais participantes, bem como da frequência com que os temas foram debatidos, foram elencadas, a posteriori, três categorias: "o imponderável 
da gestação: da invisibilidade do bebê ao vínculo inicial pai-filho"; "ontem fui filho, hoje sou pai: aspectos transgeracionais"; e "a sexualidade do homem que se tornou pai”. As categorias expostas derivam dos temas mais frequentes mencionados pelos participantes, porém não representam a totalidade dos assuntos mencionados por eles durante os encontros.

\section{RESULTADOS E DISCUSSÃO}

A seguir, serão analisadas cada uma das categorias, e fragmentos das falas dos pais serão expostos de modo a ilustrar os temas debatidos nos encontros.

\subsection{O imponderável da gestação: da invisibilidade do bebê ao vínculo inicial pai-filho}

A experiência da paternidade se apresenta singular e subjetiva para cada homem, que, de forma individual, irá sentir e viver esse momento. Assim, alguns homens precisam ter seu filho nos braços para sentirem que se tornaram pais, enquanto outros sustentam essa posição desde a gestação (Freitas et al., 2007; Krob et al., 2009).

Entre os achados deste estudo, destacou-se o fato de que os três participantes que eram pais de bebês com menos de 1 ano disseram ter se sentido pais somente após o nascimento do filho. Do mesmo modo, os dois participantes cujos filhos estavam sendo gestados mencionaram que ainda não haviam experienciado o sentimento de paternidade com a intensidade que eles imaginam que deveriam sentir após o nascimento do bebê:

Olha, não caiu a minha ficha ainda... Mas acho que a experiência de ser pai[. . .] é uma experiência ímpar, né? Ter um bebezinho ali, depois de esperar nove meses naquela expectativa. Deve ser uma experiência muito legal, bem diferente de quando está na barriga, né? (P2).

"É difícil cair a ficha, né? [...] Às vezes, nem tá formadinho ali, coisa e tal" (P4).

Eu não, eu não tinha tanto afeto para com o bebê na barriga da mãe, quanto depois que nasceu. [...] $\mathrm{O}$ meu afeto mesmo pelo bebê, sincero, assim, o amor de pai, só depois que tu começa a trocar, é [...] Como é que é... Interagir com o bebê. Não é a mesma situação que eu tenho da mãe, de tá dentro da barriga. [...] Eu digo assim, aquele sentimento mais profundo só depois que nasce o bebê (P1).

"Durante a gravidez, é estranho... Sei lá, não sei te falar. Acho que a relação com o bebê fica mais fácil pra mãe nesses meses" (P5). 
"A minha mulher sentiu mais ainda porque estava esperando dois, tinha dois bebês dentro dela, né?” (P3).

As falas dos participantes explicitam que a impossibilidade do contato visual e, em especial, do contato pele a pele dos pais com os bebês pode ser um fator que dificulta a emergência de sentimentos amorosos mais intensos com relação ao filho. Essa concepção se mostra, particularmente, nas ocasiōes em que os pais comparam a sua experiência com a experiência materna de estar gestando o bebê dentro do seu corpo. Segundo eles, o contato visceral da mãe com o bebê favorece o surgimento de afetos mais intensos dela com relação ao filho. Ainda que os recursos tecnológicos atuais (ultrassonografias e exames) facilitem a visibilidade do bebê, pois permitem a percepção real do feto e auxiliam no processo de personificação do bebê por parte do pai (Raphael-Leff, 1997), as falas dos participantes denotam a ideia de que nada é comparável à relação visceral proporcionada pela gestação.

Além disso, as falas de dois pais (P2 e P3) demonstram o receio de que o bebê não chegue a nascer e, portanto, a recusa (consciente ou não) por experimentar sentimentos amorosos mais intensos com relação ao bebê pode ser compreendida como uma forma de proteção dos pais com relação à não sobrevivência do bebê:

"A gente encontrou muita dificuldade com relação a médicos, né, da metade da gestação pra cá... Da metade não, desde o início, então, eu tinha medo do bebê nem vir a nascer"(P2).

"Eu tinha medo que tivesse problemas de saúde, não nascesse bem" (P3).

Assim, pode-se pensar que a dificuldade relatada pelos pais em conseguir estabelecer o vínculo com o bebê quando está dentro da barriga da mãe se apresenta tanto pela ausência de contato físico com a criança, em virtude da barreira anatômica imposta pelo corpo materno, quanto pelo receio de que alguma condição orgânica do bebê não viabilize a vida dele. Além disso, é desafiador, para eles, compreenderem as sensações corpóreas da mulher que gesta, e evidencia-se uma impressão de estranheza no contato deles com o bebê em virtude da inexistência de contato íntimo corporal.

Esses relatos corroboram um estudo desenvolvido por Piccinini, Levandowski, Gomes, Lindenmeyer e Lopes (2009), que mostrou que, durante a gestação, os homens não desfrutam da condição biológica de gestar e, portanto, sentemse excluídos do processo. Ademais, os pais entrevistados pelos pesquisadores demonstraram acreditar que a mulher tem privilégios na relação com o bebê, por essa relação íntima que se estabelece no empréstimo de seu corpo para gerá-lo. As falas dos participantes deste estudo, expostas a seguir, ratificam essa percepção dos pais: 
Me falaram: a mãe, a mulher é mãe desde o primeiro momento que sabe que tá grávida. O pai, eu acho que demora um pouco ainda assim. [...] Tanto que minha esposa, desde o primeiro ultrassom, ela escutava o coração e chorava e eu não conseguia... Então, eu acho que, durante a gestação, eu participei pouco. Porque... até porque ele tá dentro da barriga ainda (P2).

É, eu também não conseguia ter essa sensação de... É, eu acho que eu sou meio frio pra essas coisas também, eu sou meio frio... Conversei bem pouco. Até porque, quando eu via o bebê mexendo na barriga da, da minha esposa, eu... parecia que tava doendo em mim, porque, parece que dói na mulher quando começa a barriga a mexer (P1).

Olhar, acompanhar nos ultrassons, eu sei que é importante também. Até porque os aparelhos hoje deram uma melhorada, né? Então, a gente pode ver, se pega um profissional bom, se o tamanho tá direitinho, se o líquido tá normal. Às vezes, a mulher tem essas preocupaçōes, né? Essas dúvidas. Daí, o marido estando ali do lado dela, acalma ela, né? Mostra no ultrassom que tá tudo normal (P4).

"Mesmo após o ultrassom, eu me sentia completamente bobo. Louco da cabeça ali, né? [...] Com a barriga" (P3).

"É estranho ficar ali falando com a barriga, né?" (P5).

Apesar de, na cultura atual, haver homens que optam pelo papel de pai unicamente como provedor financeiro da família, outros estão buscando ser um novo pai, valorizando o vínculo com o filho desde a gestação (Freitas et al., 2007). Nota-se que os participantes deste estudo estão desempenhando novas práticas parentais desde o período gestacional, se comparadas às de décadas passadas, ainda que demonstrem sentir-se constrangidos ao vincular-se afetivamente com o bebê ainda sendo gestado. Ademais, segundo Freitas et al. (2007), o novo pai pode visitar o pai tradicional, mas prioriza uma paternidade mais envolvida e focada na criação do vínculo precoce, o que pode ser observado nos participantes deste estudo, ainda que eles acreditem que esse vínculo só pode ser efetivamente estabelecido depois do nascimento do bebê.

Tendo o vínculo se estabelecido após o nascimento dos bebês, pode-se observar também que as práticas de cuidar, proteger e se preocupar tornam-se recorrentes e diárias na experiência dos pais. Ressalta-se que, nos encontros em grupo, os pais discutiram muito sobre preocupaçōes voltadas ao futuro de seus filhos e da relação estabelecida entre eles, e expuseram que o vínculo estabelecido entre eles e o bebê será de fundamental importância para que a amizade e a confiança continuem estabelecidas nas fases futuras do crescimento de seus filhos.

Então, são todas essas questôes que o pai e a mãe têm que ficar, a todo momento, trabalhando e tentando colocar os filhos em um bom caminho, né? Que traga alguma coisa pra sociedade, que sejam pessoas honestas, ainda mais nesse mundo corrompido aí, que a gente conhece né (P4). 
"Eu, como pai, sempre pensei no futuro, né? [...] A questão dos valores, né? Passar pra eles essa questão" (P1).

“O pensamento é diário, a preocupação é diária, né? [...] A gente tenta desde pequeno, né? Demostrar valores" (P3).

"Até porque, hoje em dia, tem muita influência de amigos, né? Então, a gente se preocupa em dar uma educação o melhor possível, né?" (P2).

“Tem que tentar dar uma palavra de incentivo ali pro filho, né? Na hora que ele acertar, a gente motivar ele, né? Pra que depois ele não diga que meu pai, mesmo na hora de acertar, ele só me cobra, nunca me dá uma valorização" (P5).

Então, no que diz respeito ao vínculo inicial entre os pais e os bebês, evidenciouse que os pais participantes deste estudo demonstraram-se envolvidos com os seus bebês e absorvidos pelo interesse e preocupação com relação a eles, fato que demonstra a preocupação que alguns pais têm em estar buscando se aproximar afetivamente dos filhos, dialogar, bem como ser mais flexíveis e sensíveis às situaçōes cotidianas destes (Oliveira \& Silva, 2011). Assim, o diferencial do pai contemporâneo se encontra nesse envolvimento efetivo precoce, estabelecendose, assim, uma paternidade vinculada ao cuidado, ao afeto, à partilha e ao diálogo (Gomes \& Resende, 2004). As falas dos participantes sugerem que a experiência familiar e a relação estabelecida com a companheira podem ser determinantes para o surgimento desses sentimentos do pai em relação ao filho, pois, no ponto de vista dos homens, são elas que os autorizarão a se inserirem na relação com o bebê, além de serem exemplos dessa relação.

A experiência da paternidade também indica uma atualização de experiências familiares anteriores desses homens, em especial com os seus próprios pais. Tendo em vista que as falas dos participantes demonstraram que os aspectos transgeracionais também exercem influência nesse processo, esse aspecto será explorado na próxima categoria de análise.

\subsection{Ontem fui filho, hoje sou pai: aspectos transgeracionais}

O homem, ao tornar-se pai, passa por transformações que exigem a revivência das relações com o próprio pai, com a mãe, consigo mesmo e sua história como filho (Silva et al., 2012). Assim, apresenta-se a transgeracionalidade, a partir da qual o homem revive as relações parentais e atualiza conflitos e sentimentos ao tornar-se pai. A rede de relaçóes estabelecidas com o pai real ou imaginário fará com que o homem construa e reconstrua a sua subjetividade como pai (Gomes \& Resende, 2004). Então os homens que se tornam pais levam consigo o seu próprio pai como modelo, fato que exercerá influência na formação da paternidade futura de seus filhos (Gabriel \& Dias, 2011). 
No que diz respeito a esse tema, os cinco pais participantes do grupo relataram que seus pais exerceram alguma forma de influência, na maneira como eles, hoje, desempenham seu papel parental. Relataram que trazem os bons exemplos, utilizando-os na relação com seus filhos, e que procuram rever aquilo que avaliam como negativo na postura de seus pais, conforme pode-se observar nos comentários:

"Tu pega as boas e as más influências, né? [...] Mas eu tento me embasar, né? No exemplo das boas coisas" (P1).

Pra mim também teve influência do meu pai, tem influência sim. A gente sempre compara, né? Faz a comparação de como a gente foi criado, como era a atitude do pai, e de como a gente tá criando, vendo se tá sendo parecido, vendo os pontos negativos que eu achava, né? [...] Tô tentando melhorar e os pontos positivos tô tentando retificar (P3).

"Vou pegar as coisas ruins que meu pai fez comigo e não vou fazer com meu filho, quero fazer diferente, né?” (P2).

Pode-se perceber que os pais procuram repetir, na relação com os seus filhos, as atitudes que julgam ter sido acertadas na relação passada com seus pais, assim como buscam corrigir aquelas com as quais não concordam. Tentam, dessa maneira, não cometer falhas advindas de uma construção subjetiva do que é certo e errado na relação parental. Ainda, os participantes verbalizam situações do cotidiano com os seus pais, que emergem de suas lembranças. As repetições ou correçõos estão embasadas na lembrança consciente das ações passadas. Além disso, sabe-se que a repetição de modelos parentais não é completamente controlada pelo desejo consciente, pois o indivíduo se insere em uma história preexistente que lhe constitui psiquicamente e da qual faz parte como herdeiro (André-Fustier \& Aubertel, 1998).

Confere-se, então, que o tornar-se pai depende da história individual de cada homem, perpassando, ainda, a lógica do desejo (Zornig, 2012), da transgeracionalidade (Gomes \& Resende, 2004) e de aspectos marcantes da cultura (Staudt $\&$ Wagner, 2008). No que confere à cultura, em décadas passadas, cabia geralmente ao pai a tarefa e o dever de prover financeiramente a família e de atuar profissionalmente, distante da esposa e dos filhos. Esse pai, muitas vezes, era temido e respeitado, pois representava a lei e a autoridade (Lewis \& Dessen, 1999; Osório, 2002). Atualmente, não cabe ao homem somente esse papel, mas também lhe é dada a permissão de se emocionar, sofrer, sensibilizarse e experienciar prazer na relação com os filhos (Sutter \& Bucher-Maluschke, 2008). 
Nos dias atuais, compreende-se que o relacionamento entre pais e filhos está mais afetuoso e próximo (Rodrigues \& Gonçalves, 2011; Silva \& Siqueira, 2011). Nota-se, nas falas dos participantes desta pesquisa, um interesse afetivo e uma relação íntima com seus filhos, o que sugere que eles vivam uma realidade diferente daquela de seus pais e avós, que era embasada na autoridade, no distanciamento afetivo e na obediência.

Tais mudanças que ocorreram em âmbito social influenciaram os participantes deste estudo de modo que três deles percebem que a maneira como acompanharão o desenvolvimento de seus filhos será diferente da maneira como eles foram acompanhados por seus pais.

E a gente não pode querer criar só da maneira que a gente pensa, sem levar em consideração a sociedade que a gente vive. Na verdade, a gente vive em sociedade, então não tem como fugir, né? [...] Então, não adianta a gente querer criar nossos filhos da maneira que a gente foi criado, porque não vai dar certo, o mundo é outro, né? Então, por exemplo, eu não acho interessante o meu filho ir pra creche, eu não fui pra creche. Sim, eu não fui pra creche porque, naquela época, ninguém ia pra creche. Hoje em dia, é uma necessidade, todo mundo trabalha. Então, não é uma questão de escolha, é uma questão de necessidade (P3).

"Antigamente, tinha a cultura indígena, né? [...] A mulher que carregava os gravetos e o homem ia à frente. Então, muitas vezes, a cultura traz muitas coisas [...] e depois se evolui" (P4).

"A gente também já se preocupa com o além, né? Com a educação do filho, até porque o mundo que a gente vive hoje é diferente do que a gente foi criado, então, a preocupação é grande. A educação tem que ser diferente" (P2).

Percebe-se que os participantes da pesquisa demonstram interesse com relação às mudanças contemporâneas que se apresentam, principalmente no que confere ao futuro que seus filhos vivenciarão. Acreditam ser de suma importância estarem próximos e dialogando com seus filhos, desde o período mais precoce do desenvolvimento, para que a relação entre eles possa continuar embasada nesses aspectos, fortalecendo o diálogo, o companheirismo e a comunicação, e percebem a influência da cultura nesse tipo de relação.

A paternidade pode gerar ambivalência de sentimentos, e o homem, no momento de tornar-se pai, pode fazer uma reavaliação da criação e dos valores que recebeu de seus pais, assim como lembrar-se de sua própria infância. Essa condição pode levar o homem a experienciar a paternidade como uma fase conflituosa, permeada por angústias e fantasias (Gabriel \& Dias, 2011), conforme pode ser observado no relato do pai (P4): 
E eu acabei trazendo algumas características dele [do pai ${ }^{1}$ pro meu casamento, até determinados períodos... Meu pai, eu cresci vendo esse modelo e acabei trazendo ele [...] Só que, depois, eu dei um basta e disse que eu não queria mais isso pra minha vida. Então, essas coisas que você vai amadurecendo e colocando em uma balança, né?... Isso aqui eu quero pra mim, isso aqui eu não quero. Mas essa questão da gente saber o momento certo, do que foi certo e do que foi errado, do que foi absorvido dos exemplos do pai, é difícil, é muito tênue... Ah, isso é uma característica lá do meu pai que eu trouxe pra cá... A gente não percebe porque normalmente a gente acha que é perfeito, que não erra, que a gente... $\mathrm{E}$ não é isso, a gente é ser humano e em qualquer coisa vai ter erro, vai ter problema. A questão é a gente analisar e ver, isso não é bom, e isso acontece (P4).

Por essa fala, compreende-se que, muitas vezes, o modelo que foi vivenciado com seu pai durante a infância acaba se confundindo com a prática que hoje está sendo exercida, fato que vem a confirmar que a transgeracionalidade se manifesta para além dos desejos conscientes. Esse participante mostra o quão desafiador pode ser a transposição do modelo parental recebido, mesmo tendo sido identificado algum descontentamento do homem com relação à postura de seu pai.

De todo modo, percebe-se que os participantes estão buscando se tornar participativos e envolvidos com os seus filhos, o que demonstra seu desejo de superar o distanciamento vivenciado na relação com seus pais, de modo que o modelo tradicional de paternidade vem sendo transposto por eles através do resgate de suas experiências como filhos e da redefinição de papéis, conforme pode ser observado nas falas a seguir:

Um exemplo que eu tenho, né? [O pai] não precisou, pra me educar, me bater, né? $\mathrm{E}$ eu nunca bati em nenhum dos meus filhos, e é interessante. Porém o meu pai bebia muito, tinha o problema do alcoolismo, então o que eu tento me resguardar. Às vezes, não dá, né? (P1).

$\mathrm{Na}$ verdade, o meu pai nunca foi presente, né? Até porque ele foi pai muito novo, né? Quando eu nasci, ele tinha 18 anos [...] Até hoje eu nem culpo ele, porque ele era muito novo, inexperiente e não teve isso do pai dele também. [...] É aquela história, né? [...] Eu quero dar pro meu filho aquilo que eu não tive. Então, se eu não tive a presença do meu pai, eu quero ser presença pro meu filho. Pegar ele, sair final de semana pra dar uma volta, sei lá, jogar futebol com ele, não sei (P2).

As falas acima, dos pais P1 e P2, corroboram a sugestão de Gabriel e Dias (2011) sobre o desejo de os pais ensinarem a seus filhos, orientá-los e aconselhálos, oferecendo-lhes a possibilidade de terem experiências e fazerem escolhas diferentes daquelas que eles próprios não tiveram como filhos. Para isso, não se baseiam somente na maneira como foram educados ou na interação que tiveram com seus pais, mas também no modelo que eles têm no imaginário de como deve ser um bom pai.

1 Ao longo do trabalho, serão usados colchetes para o esclarecimento de informações imprecisas nas falas dos participantes. 
Além das preocupações referidas anteriormente, pode-se perceber, pelos relatos dos participantes deste estudo, que eles se preocupam em transmitir valores que consideram importantes e que são conquistados na presença dos pais:

Eu vejo que, a partir do momento que eu era solteiro e casei, o momento que eu mais prosperei, em todos os aspectos da minha vida, foi no momento que eu tive minha filha, [...] trocar filhos por uma carreira, que pode ser passageira? [. . .] Então, eu acho isso um absurdo (P4).

Ser pai é a maior responsabilidade da vida da gente, né? [...] É a vida que segue, né? E, sem dúvida, é a maior responsabilidade da vida da gente [...] Sem dúvida é o que vai... que transforma a vida, o que muda radicalmente nossa maneira de pensar a vida e muda nossa maneira de se relacionar com o mundo, com as outras pessoas... De pensar a vida (P3).

É o fechamento do ciclo, né? [...] Tu não é ninguém só com um bom emprego, um bom salário (P1).

Tem que dar carinho... Dedicar um tempo livre pra realmente estar com o filho, com a família, né? Até pro filho aprender, quando tiver a família dele, se espelhar no pai, né? [...] Mas, hoje em dia, os verdadeiros valores estão sendo deixados de lado (P2).

Assim, pode-se perceber que a relação vivida entre os participantes deste estudo com seus próprios pais, a cultura atual e o imaginário do que é ser um bom pai exercem influência no relacionamento atual entre os participantes do estudo e seus bebês. Dessa forma, muitas vezes, há intenção, nesses pais, de agir como seus pais em determinadas situaçóes, mas, em outros momentos, eles percebem que devem agir de modo diferente (Dantas, Jablonski \& Féres-Carneiro, 2004). Além das mudanças ocorridas nesse processo de revivência parental, a experiência da paternidade traz modificaçõos também na relação íntima entre o homem e a mulher, que se manifesta também na experiência sexual, fato que será discutido na categoria a seguir.

\subsection{A sexualidade do homem que se tornou pai}

O tema sexualidade tem sido cada vez mais frequentemente debatido nas escolas, nas famílias e pela mídia na atualidade. Apesar disso, ainda há aspectos relacionados a esse assunto que são pouco falados ou estudados, como é caso da gestação e no período pós-parto (Vanelli \& Silva, 2011). Sabe-se que a gestação traz consigo muitas descobertas e mudanças. O corpo da mulher modifica, os interesses e preocupações passam a ser outros, assim como as carícias e as relações sexuais entre o casal podem, também, modificar-se (Silva \& Figueiredo, 2005). 
Ressalta-se que a temática da sexualidade engloba, além do ato sexual em si, a relação conjugal, as demonstraçôes de afeto, carícias, conversas íntimas e a compreensão mútua (Canavarro, 2001). Além disso, cada um tem uma forma de vivenciar a sexualidade, sendo influenciada por fatores biológicos, sociais e culturais.

O período da gravidez e pós-parto caracteriza-se, então, por um conjunto de alterações no corpo da mulher e por mudanças psicológicas e sociais intensas também no homem. De forma consciente ou inconsciente, esse conjunto de alteraçōes reverberará na vivência da sexualidade (Silva \& Figueiredo, 2005). Assim, a gestação se apresenta como um momento único na vida de um casal, sendo, muitas vezes, vista como uma passagem para a vida adulta e a efetivação do ciclo familiar (Maldonado, Dickstein \& Nahoum, 1997).

Os pais participantes deste estudo relataram que, durante o período gestacional, a intimidade com a esposa, a troca de carícia e afeto não ocorreram da mesma forma e frequência de antes, pois, muitas vezes, eles não sabiam o quanto a relação sexual em si poderia interferir na saúde do bebê e preocupavam-se com a possibilidade de causar algum desconforto físico à esposa e ao feto durante as carícias e a penetração. Mesmo quando a esposa lhes dizia que estava tudo bem, eles permaneciam receosos com a prática sexual. Nota-se, ainda, que, apesar dessa insegurança, os homens referem que as mudanças corporais advindas durante a gestação não reduziram o desejo sexual e interesse pelas companheiras:

Medo sim, medo, receio [...] A gente não conhece como é o aparelho... aparelho... ginecológico ali da mulher, né? [...] Receio sim, né? [...] Muda tudo, mas ela falava que era tranquilo, que não sentia incômodo nenhum. E com relação à atração, ficou tudo normal, não mudou muito assim, né? (P3).

“Às vezes, era estranho. Não sabia se devia fazer, mas depois rolava” (P1).

A gente costuma falar que a grávida mais bonita é a da gente, a grávida mais bonita do mundo é a da gente... Mas, pra mim, eu tentei fazer tudo normal assim, sem problemas, né? [...] O ser humano se adapta muito facilmente... Claro que tiveram mudanças, mas tentei me adaptar" (P5).

As mudanças físicas no corpo da mulher grávida são evidentes, e nota-se, nas falas dos participantes, que o apreço pela companheira e a preocupação com a saúde do bebê são fatores que, inevitavelmente, incidem sobre a experiência sexual do homem. Além disso, após o nascimento, o tempo, para o casal, é reduzido, a atenção dispensada pela mulher ao homem e vice-versa será dividida com o bebê, portanto a disposição e o interesse por manter relações sexuais poderão diminuir. Pelos relatos dos participantes deste estudo, pode-se perceber 
que essa sensação de afastamento do casal é percebida pelos homens, mas tida por eles como uma consequência natural advinda das novas exigências após o nascimento do bebê.

"Isso aí é natural, né? Tem que dar atenção ao bebê, não adianta, vai acontecer... A mãe e o pai se envolvem com o bebê" (P3).

"A minha esposa já tá reclamando, né? [...] Eu tô dando mais atenção pro bebê do que pra ela" (P2).

"Começa a olhar mais pro lado dos filhos, né?" (P1).

Louro (1997) expõe que as responsabilidades que a paternidade traz consigo acarretam diferentes formas de viver os prazer e desejos corporais. $\mathrm{O}$ homem vive em processo de fusão entre o mundo do trabalho, da sensibilidade paterna e da sua virilidade sexual (Nolasco, 1993). Pode-se pensar que as exigências e realizações no primeiro mês após o nascimento do bebê têm grande repercussão na experiência do homem, que se sente satisfeito, cansado e absorvido pelo bebê, não atentando para os seus desejos sexuais:

"É tanta novidade que passa tudo muito rápido, né? [...] A gente fica muito envolvido nesses 30, 40 dias ali” (P3)

“E a criança ali, tudo é novo em casa, tu nem lembra do sexo. É contornável, né?” (P4).

"E depois tem a visita da sogra, né? Que vem pra ajudar, fica ali, duas semanas... Então, voa mesmo, né? A gente nem tem muito tempo de pensar nisso [ato sexual]" (P5).

Apenas um dos participantes, em tom de brincadeira, relatou que o período da quarentena não foi tranquilo no que se refere à ausência de interações sexuais com a companheira. Esse relato pode ser analisado pela perspectiva de Chauí (1991), que propóe que, culturalmente, a abstinência sexual deve ser realizada pela mulher enquanto ela se recupera do parto, enquanto que ao homem é permitida, de forma oculta, a prática sexual com outras mulheres ou com prostitutas. Há, na nossa cultura, a ideia de que o homem necessita atender a seus desejos instintuais relativos à satisfação sexual, enquanto que o mesmo não é pensado sobre as mulheres. "Eu acho que tu [a pesquisadora] poderia sugerir pras esposas de na quarentena dar o passe livre. Uma hipótese é o passe livre para aliviar todo o pós (risos)" (P1).

A respeito desse tema, há estudos que demonstram que, durante a gravidez, o casal já percebe mudanças em sua vida sexual, e as alteraçóes no corpo da mulher, somadas ao grande interesse dos dois pelo bebê, são os fatores preponderantes 
para a redução das relações sexuais com penetração. Os casais tendem a buscar novas formas de satisfação do prazer sexual (Facco \& Kruel, 2013). Além disso, em alguns casos, a atividade sexual após o parto se torna praticamente inexistente, em especial por falta de interesse e por uma indisponibilidade da mulher (Silva \& Figueiredo, 2005). Essa falta se relaciona à recuperação do parto, podendo ser consequência do desconforto físico sentido pela mulher em decorrência dos procedimentos deste, assim como pelo aumento da prolactina e às alterações hormonais, quanto ao ajuste nas mudanças de papéis advindos do nascimento do bebê.

A redução do desejo sexual da mulher pode gerar insegurança no homem quanto às suas atitudes diante da mulher, assim como com relação à sua performance sexual. Por diferentes razôes, a mulher pode deixar o parceiro e a relação sexual em segundo plano, fato que pode ocasionar descontentamento do homem diante da relação íntima estabelecida entre mãe e bebê. Deve-se salientar que a intensidade dessas mudanças é extremamente variável (Balonne \& Moura, 2008).

Neste estudo, os três pais cujos filhos tinham idade entre 18 dias e 7 meses, não se sentiram dispostos para atividades sexuais nos primeiros dias após o nascimento do filho, porém, no decorrer dos meses, a ausência afetiva e sexual da companheira passou a ser questionada. Como alternativa para reduzir o desconforto sentido, os participantes mencionaram a importância do diálogo com a companheira e os espaços em que podem compartilhar com outros homens que vivenciam experiências semelhantes:

A gente fica só em função dos filhos, dos filhos, não tem tempo pro convívio com a esposa [...] E a minha esposa, é complicado... O temperamento dela muda com frequência... Ali com a criança, ela tem mais trabalho, tem que dar $100 \%$ de atenção à criança, atenção pro bebê [...] Então, com certeza... Como eu vou dizer, a tolerância da esposa, ela se torna uma coisa mais improvável. [...] Então, a gente deixar de lado a privacidade do casal, a gente deixar bastante coisa de lado, é um fator negativo de se tornar pai (P1).

"A mulher é mais sensível, mas acaba entrando em uma rotina, né? [...] Daí fica complicado" (P5).

Mas é muito bom a gente entrar, conversar sobre esse assunto, principalmente aqui, que todo mundo vivencia o mesmo momento... Porque a gente entra em uma neura... É comigo, é só comigo... Não me acerto mais com a mulher... Não vai dar mais certo (P3).

Além das alternativas mencionadas, um dos participantes deste estudo considerou importante que o casal preserve momentos de intimidade distante dos filhos: 
Tem os momentos de brigas, né? [...] Isso é óbvio que tem. Família perfeita não existe, mas que ela possa ver que sobrepuja o amor, a compreensão dentro de casa, né? E esse momento, nem que seja uma vez por ano, tem que ter ali, ir viajar sozinho, sem os filhos [...] Enfim. Daí tem que arrumar alguém, talvez um familiar mais próximo (P4).

Percebe-se, então, que o homem, ao tornar-se pai, sofre adaptações em todos os aspectos de sua vida, inclusive em sua sexualidade. Para os pais participantes deste estudo, compreende-se que a ausência da relação sexual é tida como normal no período em que eles estão vivenciando, de forma mais intensa, as mudanças advindas com a chegada do bebê, porém, no decorrer do primeiro mês, essa ausência é tida como fator negativo. Os participantes do estudo acreditam que a satisfação do seu desejo sexual deva se aliar aos prazeres da paternidade.

\section{CONSIDERAÇÕES FINAIS}

Tendo em vista que este trabalho objetivou analisar a experiência do homem, ao tornar-se pai, no contexto gestacional e nos primeiros meses de vida do bebê, com enfoque no vínculo inicial, aspectos transgeracionais relativos ao cuidado e influência do tornar-se pai na sexualidade desse homem, buscou-se identificar o papel que está sendo desempenhado pelo pai no cotidiano da gravidez e dos primeiros meses após o nascimento do filho, assim como seus sentimentos em relação a essas vivências. Foi possível constatar que, durante a gestação, os pais encontraram dificuldade para se vincularem ao bebê, e isso se justifica pela barreira física existente entre ambos, ausência de sensações corpóreas do pai por sua condição de não gestar o bebê e como medida protetiva diante da dúvida quanto à sobrevivência do bebê. Portanto o vínculo do pai com o bebê tende a se consolidar após o nascimento do filho, momento no qual o contato físico com a criança bem como a interação ativa viabilizam o emergir de sentimentos e desejos reais, em que cuidar, proteger, afagar e amar o filho passam a fazer parte da relação entre pai e bebê.

Assim, a relação passa a ser alicerçada na intimidade, na confiança e nos cuidados com o(s) filho(s). Atualmente, o papel de cuidador está tendendo para mudanças que perpassam as questôes de gênero, nas quais os papéis de mãe e pai não são rígidos e se complementam. Percebe-se que esse novo pai não se contenta em ser somente o provedor da casa, buscando o seu espaço afetivo na relação parental.

Constatou-se também que a transgeracionalidade está presente nesse processo de tornar-se pai, pois a experiência da paternidade está invariavelmente vinculada ao modelo observado e vivenciado na relação do homem com seu próprio pai. Assim, as questôes de cuidado e atenção podem ser revividas ou modificadas, 
de acordo com a percepção de certo ou errado trazidas consigo da sua vivência pessoal passada.

Destacou-se o fato de que o nascimento do bebê afeta a experiência sexual do homem, na qual o distanciamento sexual da companheira é compreendido nos primeiros dias após o nascimento do filho, apesar de, com o decorrer dos meses, a ausência afetiva e sexual da companheira passar a ser questionada. Como alternativa para reduzir esse desconforto, o diálogo com a companheira e o estabelecimento de espaços em que possam compartilhar, com outros homens, experiências semelhantes se mostram importantes.

Cabe mencionar o fato de todos os participantes serem militares, e sugere-se que estudos futuros investiguem a experiência da paternidade com um grupo de pais que exerçam profissões diferentes, nas quais experiências diferenciadas podem se apresentar de acordo com a ocupação profissional. Ainda, sugerese que pesquisas sobre o tema sejam realizadas com pais de diferentes níveis socioeconômicos e culturais para que, assim, averigue-se qual a relação existente entre a prática parental e a cultura na qual estão inseridos os sujeitos. Por fim, almeja-se que este estudo favoreça o olhar sobre a experiência da paternidade em período precoce do desenvolvimento infantil e que inaugura a experiência parental. 


\section{REFERÊNCIAS}

André-Fustier, F. \& Aubertel, F. (1998). A transmissão psíquica familiar pelo sofrimento. In A. Eiguer. A transmissão do psiquismo entre geraçôes: enfoque em terapia familiar psicanalitica. (pp. 129-179). São Paulo: Unimarco.

Balancho, L. S. F. (2004). Ser pai: transformações intergeracionais na paternidade. Análise Psicológica, 2, 377-386.

Ballone, G. J. \& Moura, E. C (2008). Gravidez e sexualidade. [S.I.]: PsiqWeb. Recuperado a partir de http://www.psiqweb.med.br/site/?area=NO/ LerNoticia\&idNoticia $=141$

Bardin, L. (2004). Análise de conteúdo. (3a ed.). Lisboa: Edições 70.

Campos, L. F. L. (2004). Métodos e técnicas de pesquisa em psicologia. (3a ed.). Campinas: Alínea.

Canavarro, M. C. (2001). Psicologia da gravidez e da maternidade. Coimbra: Quarteto.

Chauí, M. (1991). Repressão sexual: essa nossa (des)conhecida. São Paulo: Brasiliense.

Dantas, C., Jablonski, B. \& Féres-Carneiro, T. (2004). Paternidade: considerações sobre a relação pais-filhos após a separação conjugal. Paidéia, 14(29), 347-357. Recuperado a partir de http://www.scielo.br/pdf/paideia/v14n29/10.pdf

Facco, D. \& Kruel, C. S. (2013). "O meu corpo mudou tão depressa": as repercussões da gravidez na sexualidade feminina. Disciplinarum Scientia. Série: Ciências Humanas, 14(2), 141-155. Recuperado a partir de: http://sites.unifra. br/Portals/36/CHUMANAS/2013-2/04\%20O\%20MEU\%20CORPO\%20 MUDOU\%20T\%C3\%87O\%20DEPRESSA.pdf

Ferreira, F. H. et al. (2016). Experiência paterna no primeiro ano de vida da criança: revisão integrativa de pesquisas qualitativas. Revista Eletrônica de Enfermagem, 17(3). Recuperado a partir de http://dx.doi.org/10.5216/ree. v17i3.29300

Freitas, W. M. F., Coelho, E. A. C. \& Silva, A. T. M. C. (2007). Sentir-se pai: a vivência masculina sob o olhar de gênero. Caderno de Saúde Pública, 23(1), 137-145. 
Freitas, W. M. F., Silva, A. T. M. C., Coelho, E. A. C., Guedes, R. N., Lucena, K. D. T. \& Costa, A. P. T. (2009). Paternidade: responsabilidade social do homem no papel de provedor. Revista de Saúde Pública, 43(1).

Gabriel, M. R. \& Dias, A. C. G. (2011). Percepções sobre a paternidade: descrevendo a si mesmo e o próprio pai como pai. Estudos de Psicologia, 16(3), 253-261. Recuperado a partir de http://www.scielo.br/pdf/epsic/v16n3/07. pdf

Gil, A. C. (2007). Métodos e técnicas de pesquisa social. São Paulo: Atlas.

Gomes, A. J. S. \& Resende, V. R. (2004). O pai presente: o desvelar da paternidade em uma família contemporânea. Psicologia: Teoria e Pesquisa, 20(2), 119-125. Recuperado de http://www.scielo.br/scielo.php?script=sci_ arttext\&pid=S0102-37722004000200004

Henningen,I. \& Guareschi, N.M.F.(2002). Apaternidadenacontemporaneidade: um estudo de mídia sob a perspectiva dos estudos culturais. Psicologia $e$ Sociedade, 14(1), 44-68. Recuperado a partir de http://www.lume.ufrgs.br/ handle/10183/20634?locale=pt_BR

Iervolino, S. A. \& Pelicioni, M. C. F. (2001). A utilização do grupo focal como metodologia qualitativa na promoção de saúde. Revista da Escola de Enfermagem da USP, 35(2), 115-121. Recuperado a partir de http://www.scielo.br/pdf/ reeusp/v35n2/v35n2a03.pdf

Krob, A. D., Piccinini, C. A. \& Silva, M. R. (2009). A transição para a paternidade: da gestação ao segundo mês de vida do bebê. Psicologia USP, 20(2), 269-291.

Lewis, C. \& Dessen, M. A. (1999). O pai no contexto familiar. Psicologia: Teoria e Pesquisa, 15, 9-16.

Louro, G. L. (1997). Gênero, sexualidade e educação: uma perspectiva pósestruturalista. Petrópolis: Vozes.

Maldonado, M. T., Dickstein, J. \& Nahoum, J. C. (1997). Nós estamos grávidos. (10a ed.). São Paulo: Saraiva.

Minayo, M. C. S. (2007). O desafio do conhecimento: pesquisa qualitativa em saúde (10a ed.). São Paulo: Hucitec.

Nolasco, S. (1993). O mito da masculinidade. Rio de Janeiro: Rocco. 
Oliveira, A. G. \& Silva, R. R. (2011). Pai contemporâneo: diálogos entre pesquisadores brasileiros no período de 1998 a 2008. Revista Psicologia Argumento, 29(66), 353-360.

Osório, L. C. (2002). Casais e famílias, uma visão contemporânea. Porto Alegre: Artmed.

Piccinini, C. A., Levandowski, D. C., Gomes, A. G., Lindenmeyer, D. \& Lopes, R. S. (2009). Expectativas e sentimentos de pais em relação ao bebê durante a gestação. Estudos de Psicologia, 26(3), 373-382. Recuperado a partir de http://www.scielo.br/scielo.php?script=sci_arttext\&pid=S0103166X2009000300010

Raphael-Leff, J. (1997). Gravidez: a história interior. Porto Alegre: Artes Médicas.

Rodrigues, P. M. \& Gonçalves, C. S. (2011). "Pai deve participar": reflexões sobre a paternidade na atualidade. In F. P. Jaeger, C. S. Kruel \& A. C. Siqueira (Orgs.), Parentalidade e contemporaneidade: os desafios para a Psicologia. (pp. 77-99). Santa Maria: Centro Universitário Franciscano.

Silva, A. I. \& Figueiredo, B. (2005). Sexualidade na gravidez e após o parto. Psiquiatria Clínica, 25(3) 253-264. Recuperado a partir dehttps://repositorium. sdum.uminho.pt/bitstream/1822/4720/1/sexualidade $\% 20$ na $\% 20$ gravidez. pdf

Silva, E. L. C., Lamy, Z. C., Rocha, L. J. L. F. \& Lima, J. R. (2012). Paternidade em tempos de mudança: uma breve revisão da literatura. Pesquisa e Saúde, 13(2), 54-59. Recuperado a partir de http://www.huufma.br/site/estaticas/ revista_hu/pdf/Revista_maio-agost-2012.pdf

Silva, J. K. \& Siqueira, A. C. (2011). Ser pai e ser mãe após a separação conjugal: compreendendo as dificuldades impostas no exercício da parentalidade pela síndrome da alienação parental. In F. P. Jaeger, C. S. Kruel \& A. C. Siqueira (Orgs.), Parentalidade e Contemporaneidade: os desafios para a Psicologia. (pp. 33-54). Santa Maria: Centro Universitário Franciscano.

Staudt, A. C. P. \& Wagner, A. (2008). A paternidade em tempos de mudança. Psicologia: Teoria e Prática, 10, 174-185.

Sutter, C. \& Bucher-Maluschke, J. S. N. F. (2008, janeiro- março). Pais que cuidam dos filhos: a vivência masculina na paternidade participativa. Psico, 39(1), 74-82. 
Vanelli, C. \& Silva, J. C. (2011, 24 dezembro). Sexo na gestação na percepção masculina. Psicologia. PT. Recuperado a partir de http://www.psicologia.pt/ artigos/textos/TL0253.pdf

Zornig, S. M. J. (2012). Construção da parentalidade: da infância dos pais ao nascimento dos filhos. In Piccinini, C. A. \& Alvarenga, P. (Orgs). Maternidade e paternidade: a parentalidade em diferentes contextos. (pp. 37-63). São Paulo: Casa do Psicólogo. 